\title{
Educação ambiental, gênero, sexualidade e luta de classes: algumas reflexões sobre política, educação crítica e transformação social
}

\section{Mateus Luiz Biancon ${ }^{1}$ e Flávia Wegrzyn Martinez²}

1 Doutor em Educação para a Ciência e a Matemática pela Universidade Estadual de Maringá (UEM). Professor Adjunto B do Centro de Ciências Humanas e da Educação do Colegiado de Ciências Biológicas. Professor do Programa de Pós-Graduação lato sensu em Humanidades, Brasil. E-mail: mateusbiancon@uenp.edu.br

2 Doutoranda em Educação pela Universidade Estadual de Ponta Grossa (UEPG). Professora do Centro de Ciências Humanas e da Educação - CCHE. Universidade Estadual do Norte Do Paraná- UENP/CJ- Colegiado de Pedagogia, Brasil. E-mail: fwmartinez@uenp.edu.br

RESUMO: A educação ambiental e as questões de gênero e sexualidade contribuem para o processo de emancipação humana e devem ser discutidas na educação escolar, especialmente na escola pública. Visto que o desenvolvimento de um processo que objetiva a construção de uma sociedade igualitária e justa, só pode ocorrer a partir dos embates dentro do modo de produção capitalista, ou seja, a partir de um processo histórico de luta, defende- se que as discussões sobre as questões de gênero e sexualidade bem como a educação ambiental devem orientar-se a partir da filosofia da práxis. Desta forma, a partir de Saviani $(2005,2008,2011)$, Lukács $(1969,1978,1979)$, Biancon, (2016), este artigo tem como objetivo apresentar a necessidade da participação política para a transformação da sociedade contemporânea e analisar o papel da educação crítica no processo de transformação social considerando a educação ambiental e as discussões de gênero e sexualidade e a luta de classe. Como método de análise adotou-se o materialismo histórico dialético.

Palavras-chave: Educação ambiental. Políticas públicas. Gênero e Sexualidade.

Environmental education, gender, sexuality and class struggle: some meditations on politics, critical education and social transformation

ABSTRACT: Environmental education and issues on gender and sexuality contribute to the process of human emancipation and must be debated in the educational system, mainly in public schools. Since the development of a process that aims at constructing an equal and fair society can only appear from the clashes inside the capitalist mode of production, that is, from a historical process of conflict, it is defended that the debates over gender and sexuality, as well as over environmental education, should be directed by the philosophy of praxis. Thus, starting from Saviani $(2005,2008,2011)$, Lukács $(1969,1978,1979)$ and Biancon (2016), this article has the purpose of presenting the demand on political participation forthe transformation of contemporary society, and analyzing therole of critical education in the process of social transformation, taking into account environmental education, gender and sexuality discussions and class struggle. As a method of analysis, the Historical and Dialectical Materialism approach was adopted.

Keywords: Environmental education. Public policies. Gender and sexuality. 


\section{INTRODUÇÃO}

Este estudo relaciona-se à educação ambiental e às questões de gênero e sexualidade no contexto educacional, comprometidas com a transformação social e consequentemente com a luta de classes, já que esta perspectiva de educação não pode conceber mudanças na relação entre humanos e natureza que não estejam articuladas às mudanças das relações que os seres humanos estabeleceram com seus semelhantes ao longo de sua história.

Entende-se que o mais elevado grau de desenvolvimento humano processa-se em sua manifestação política que, no processo de produção material impõe-se como agente da justiça social, visando à igualdade na diversidade entre os seres humanos. Nesse entendimento, o desenvolvimento de um processo que objetiva à construção de uma sociedade igualitária e justa, só pode ocorrer a partir dos embates dentro do modo de produção capitalista, ou seja, a partir de um processo histórico de luta.

Marx (1977, p. 24), coloca que "omodo de produção da vida material condiciona o desenvolvimento da vida social, política e intelectual em geral. Não é a consciência dos homens que determina o seu ser; é o seu ser social que, inversamente, determina a sua consciência". Para Marx, os sistemas políticos, os princípios jurídicos e as ideologias não têm vida própria perante o modo pelo qual os homens produzem e reproduzem a existência. Assim, Marx, atribui às relações de trabalho e produção, ou seja, aos fatores econômicos um valor basilar na conjuntura dos acontecimentos históricos. Neste contexto, a consciência do homem não fundamenta essas relações, mas é resultado delas, bem como os sistemas conceituais (direito, moral, sistema politico, religião, ideologia e educação), a superestrutura da sociedade, são derivados da estrutura econômica. $\mathrm{O}$ autor compreende dessa forma, o ser humano, como ser social, histórico, produtor e produto das relações sociais.

Neste sentido, apreendemos a educação por meio das lutas históricas do gênero humano. Saviani (2005, p.248), explica que "com o advento da sociedade moderna, capitalista, burguesa, a educação escolar, antes restrita a poucos, tende a se generalizar, convertendose na forma principal e dominante de educação." Parece-nos óbvio que a educação é o principio ativo com os atributos necessários para conduzir os indivíduos a sua realização como ser humano emancipado. Neste ínterim, a pedagogia histórico-crítica considera primordial a função do professor em transmitir aos alunos o saber sistematizado produzido pelo gênero humano no decorrer da história (SAVIANI, 2008). Visto que o processo de reconhecimento da cultura como produção imanente à atividade humana desencadeia o desenvolvimento da consciência, que por sua vez, possibilita a humanização dos indivíduos. Saviani (2007)caracteriza este processo como passagem do senso comum à consciência filosófica, processo esse que não é simples e nem rápido, uma vez que alude: "[...] passar de uma concepção fragmentada, incoerente, desarticulada, implícita, degradada, mecânica, passiva e simplista a uma concepção unitária, coerente, articulada, explícita, original, intencional, ativa e cultivada" (p. 3).

Nesta perspectiva, este trabalho justifica-se por entendermos que a educação ambiental 
e as questões de gênero e sexualidade contribuem com o processo de emancipação humana por sua especificidade relacionada às abordagens críticas em relação à problemática da luta de classes contemporânea e por isso a importância da discussão na escola pública. A afirmação anterior deve-se a diversas manifestações educativas em educação crítica que apontam para a necessidade da inserção de discussões políticas no âmbito destas áreas do conhecimento. Todavia, a condição fundamental para a inserção dos ditames críticos somente pode ocorrer articulando-se a filosofia da práxis no processo formativo da educação ambiental bem como para as discussões de gênero e sexualidade na educação escolar.

Diante de tais considerações, o objetivo deste texto é apresentar a necessidade da participação política para a transformação da sociedade contemporânea e analisar o papel da educação crítica no processo de transformação social considerando a educação ambiental e as discussões de gênero e sexualidade e a luta de classe.

Pelo exposto, adotamos o materialismo histórico dialético como método de análise (MARX, 2010, p.28), pois entendemos que este enfoque teórico:

Contribui para desvelar a realidade, pois busca apreender o real a partir de suas contradições e relações entre singularidade, particularidade e universalidade. Esse enfoque tende a analisar o real a partir do seu desenvolvimento histórico, da sua gênese e desenvolvimento, captando as categorias mediadoras que possibilitam a sua apreensão numa totalidade. Assim, tal enfoque constitui-se num referencial consistente, ou seja, um "refletor poderoso" para a análise das políticas educacionais [...] (MASSON, 2012, pp. 2-3).

Nesta perspectiva é possível analisar as discussões de gênero, sexualidade, ambiente e a luta de classe no contexto educacional nos pólos singular, particular e universal, compreendendo que a singularidade se produz na universalidade à maneira e ao mesmo tempo em que a universalidade se efetiva na singularidade mediada pela particularidade, isto é, a sociedade do capital é responsável pela mediação entre o indivíduo (singular) e o gênero humano (universal). $O$ afastamento do indivíduo ao patrimônio genérico universal condena-o ao domínio dos particularismos, levando-o à alienação (PASQUALINI; MARTINS, 2015).

É nesse sentido que se entende a necessidade de apreender o conhecimento da realidade indo do empírico ao concreto por meio das abstrações da mente. Tal ação permite superar o imediatismo que impede o desvelar da essência dos fenômenos. Ainda contribui substancialmente para a elaboração de categorias de análise que caracterizam a objetividade como centralidade da produção do conhecimento científico, artístico e filosófico.

No intento de compreender a realidade em sua totalidade, faz-se necessário desvelar as relações, que são captadas na perspectiva de totalidade. Visto que, a totalidade existe a partir das mediações, onde as totalidades parciais encontram-se entrelaçadas a várias determinações que se modificam constantemente. Assim,Lukács (1969) compreende a sociedade como um "complexo de complexos" (p.16) e, nesse sentido, a educação torna-se objeto da reflexão ontológica, visto que é um dos complexos que fazem parte da sociedade. "Todavia, como o ser da sociedade é histórico, a essência ontológica da educação só pode ser apreendida em uma perspectiva historicizadora." (LUKÁCS, 1969, p.160). Desse modo, 
faz-se necessário questionar se o fato da ciência ser desantropomorfizadora significa que esse tipo de reflexo da realidade privilegia a razão em detrimento da emoção e da sensibilidade. Assim, é imprescindível frisar que apesar de seu caráter desantropomorfizador, a objetividade científica também se volta ao ser humano, como bem expressa Lukács (1966a, p. 184):

[...] o reconhecimento de leis da realidade em si, independentes da consciência humana, se converte aqui em veículo da consciência da consecução da liberdade do homem, de sua liberdade como penetração intelectual nas forças reais objetivas que apenas pode ter mediante um conhecimento adequado, para desmascarar aquelas outras forças imaginárias, inconscientemente produzidas pelo homem mesmo e que este não poderá superar senão mediante tal esclarecimento da sua essência.

Do mesmo modo, Marx, a partir da crítica ontológica, objetiva "[...] despertar a consciência científica no sentido de restaurar no pensamento a realidade autêntica, existente em-si", (LUKÁCS, 1979, p.27), pois a partir da ontologia é possível compreender o movimento da realidade histórica na sociedade capitalista. Sendo que pela análise crítica e perspectiva histórica, é possível apreender as ações humanas, considerando a particularidade e a universalidade. Nesse sentido, Lukács (1978) esclarece que o particular é a demonstração lógica das categorias de mediação entre o gênero humano e a sociedade. Assim a relação entre singular e universal é permeada pelo particular.

Pois, atribuir ao pensamento humano uma verdade objetiva não é "uma questão teórica, mas prática, visto que é na práxis que o homem deve demonstrar a verdade, isto é, a realidade e a força, o caráter terreno de seu pensamento." (MARX; ENGELS, 2006, p.120). A práxis é atividade livre, criativa, a partir da qual é possível transformar o mundo e a si mesmo.

\section{POLÍtICAS PÚBLICAS EM EDUCAÇÃo AMBIENTAL E PARA AS DISCUSSÕES DE GÊNERO E SEXUA- LIDADE NO CONTEXTO EDUCACIONAL}

A palavra política tem sua gênese no grego e denota-se limite, conforme aponta Sarmentino (2005). O muro que delimitava a cidade do campo denominava-se de polis, somente depois se passou a designar polis o que estava contido no interior dos limites do muro. "O resgate desse significado, como limite, talvez nos ajude a entender o verdadeiro significado da política, que é a arte de definir os limites, ou seja, o que é o bem comum" (GONÇALVES, 2002, p. 64). Nesse sentido, as políticas públicas voltadas àeducação ambiental necessita comprometer-se à superação das injustiças ambientais, da desigualdade social, da apropriação capitalista e funcionalista da natureza, bem como da própria humanidade. Entretanto, experenciamos processos de exclusão, degradação ambiental socializada atrelada a apropriação privada dos benefícios materiais gerados.

Desse modo, a educação ambiental crítica precisa resistir à dominação capitalista, pois em nosso entender, a preocupação com o ambiente e as discussões de gênero e sexualidade no processo educativo explicitam questões atuais significativas no campo das políti- 
cas públicas, que necessitam considerar o ambiente, o gênero e a sexualidade para além do aspecto natural e naturalizante, compreendendo-o como local de disputa em que se processa a luta de classes. Da mesma maneira, a resistência a esse sistema dominante de organização societária, compreende que tanto os gêneros quanto as sexualidades

resultam das relações e determinações sociais que, sob o domínio do capital, são alienadas. Essas determinações sociais é como produzimos a vida em sociedade em que o sistema capitalista determina a lógica econômica, social e política, refletindo na educação e na formação dos seres humanos. Assim, a sexualidade (que pode ser mutável) é um elemento central e essencial da constituição dos humanos (em sua dimensão biológica e psicológica), embora construída e "naturalizada" nas suas relações sociais e históricas, em constante transformação da sociedade na produção da existência humana (o ser humano só se torna humano vivendo em sociedade, o que significa que viver em sociedade é a produção da existência humana), moldada pela hegemonia do capital. As sexualidades são alienadas pelos demais aspectos da cultura humana, encadeada e "naturalizada" pela produção cultural, como a religião, a economia, a política, a ideologia, a ciência e as relações de poder, instituída na sociedade cujo modo e as relações de produção geram entendimentos limitados para a compreensão desta expressão humana em toda a sua grandiosidade. Vivemos em uma sociedade em que tudo está determinado pelo capital ou pela lógica do capital, então, este imiscui-se em todas as instituições concepções ideológicas e constroem as formas de pensamento, sentimento, ação e como os fatores causais, isto é, a lógica do capital não são captados pela lógica formal e pelo senso comum, viabiliza, portanto, pensamentos, sentimentos, ações e relações alienadas (BIANCON, 2016, p.41 e 42).

Consideramos que a compreensão dos gêneros e sexualidades naturalizado em nossas relações sociais é fruto de um processo histórico e dialético, preconizados pela sociedade do capital. No mesmo sentido, os motivos causais da crise ambiental são reflexos direto do modo e dos meios de produção que de certa forma determina a apropriação e a degradação do espaço sócio-ambiental. Por isso, entre concepções e abordagens teórico-práticas quanto ao modo de se pensar o processo educacional, sugerimos aquela que oportunize condições para o enfrentamento à crise estrutural da organização societária (TEIXEIRA; TOZONI-REIS; TALAMONI, 2011).

Logo, entendemos a educação ambiental crítica como um processo político de apropriação crítica e reflexiva de conhecimentos, atitudes, valores e comportamentos que tem como objetivo a construção de uma sociedade sustentável do ponto de vista ambiental e social - a educação ambiental transformadora e emancipatória. (TEIXEIRA; TOZONI-REIS; TALAMONI, 2011, p.229).

O papel e a função que a educação desempenha tem como propósito o ser humano, visto que o considera como ser concreto, histórico, que relaciona-se com outros seres vivos na sociedade em que vive. Gramsci (1978b p.43-44) corrobora com esta afirmação quando analisa como a relação do ser humano com os demais seres humanos e a natureza e nos ajuda a apreender como se dá a relação hegemônica nas ações políticas e sociais e nelas inseridas as concepções educativas. Assim, para alcançar a função hegemônica, a mesma classe hegemônica agrava ao que Gramsci denomina de instituições privadas, sendo a escola considerada uma delas. 
Assim a Educação escolar é contraditória, pois sua especificidade é a socialização dos saberes sistematizados, entretanto estes saberes são também constitutivos dos meios de produção que por serem propriedades do capital, não podem ser socializados. Desse modo, o desafio é que esta especificidade de socializar o saber sistematizado se cumpra, e para tanto, é fundamental professores comprometidos e portadores de uma formação crítica e que desenvolvam práticas críticas (SAVIANI, 2011). Por isso, antes de tudo, entendemos as questões de gênero, sexualidade e da educação ambiental como educação, compreendendo como ação política, que concebe a educação como elemento de transformação social.

Nesse propósito, pensar a educação ambiental é entendê-la como forma de se criar condições para o enfrentamento da degradação ambiental que resulta do sistema organizacional de sociedade. Tendo como pressuposto a transformação social, a educação ambiental, nesse processo historicamente disputado, acirradamente, entre pedagogias tradicionais e críticas, há que se buscar um processo educativo que luta contra a manutenção do capital e a favor do ambiente. O problema que nos é posto se revela pela precariedade, deficiência na educação formal resultado de escolhas político-econômicas daqueles que representam democraticamente o povo, ao se comprometerem aos interesses privados e à manutenção do status quo (JANKE, 2012).

O mesmo ocorre ao considerar as discussões de gênero e sexualidade, que da mesma maneira, se evidencia de forma secundarizada como o anterior em termos de currículo, enfrentando um projeto hegemônico de capital, retrógrado e conservador que contribui com o processo marginalizador ao atacar as políticas públicas de gênero e sexualidade. São posturas fundamentadas na heteronormatividade, que se destaca como base sustentada pela ALGBTIQfobia, existente nas relações humanas que conformam as pessoas a um modelo afetivo, cultural e social, fruto de determinações históricas, que favorece o modo como se organiza e se produz a vida em sociedade (BIANCON, 2016).

Para Maia (2015), essa hegemonia estende-se às políticas relacionadas ao ambiente determinada por homens, brancos, heterossexuais e ricos ainda representando o atual Congresso Nacional, como a bancada BBB - Bíblia, Boi e Bala, defendendo uma agenda conservadora, pragmática, retrógrada e preconceituosa. Nesse processo de dominação e exploração, em que as políticas públicas são encaminhadas, a classe trabalhadora representa a grande parcela da sociedade a serviço de concentrar riqueza a uma minoria, porém hegemônica, denominada como donos do capital, bem como ajustar os indivíduos às normas de gênero vista pela lógica ideológica "macho e fêmea", da matriz heterossexual e apropriar de forma privada o patrimônio ambiental.

Diante deste cenário e fundamentados na concepção de ciência política no sentido que utiliza Gramsci (1999-2002) em seus cadernos do Cárcere, compreendemos a problemática ambiental, as discussões de gênero e sexualidade, a luta de classes e as políticas públicas no contexto escolar, preocupados com o ambiente e o ataque às questões de gênero e às sexualidades (singularidades) e ao acesso ao conhecimento sistematizado das discussões de gênero e sexualidade e a educação ambiental (universal) e, ainda, com o pluralismo de ideias e a diversidade cultural, incluídos elementos nele dispostos a discutir valores, cren- 
ças, costumes, preconceitos e minorias, fruto de uma ideologia pós-moderna, que pretendem superar os aspectos da educação considerados problemáticos, como gênero, sexualidade, etnia, gerações, educação do campo, confissões religiosas e ambiental (BIANCON, 2016).

Todavia, as perspectivas de superação da ordem social atual são concomitantes com a busca de superação da ordem do capital, pois os limites das lutas sociais por uma sociedade comprometida com a qualidade de vida e a valorização das trabalhadoras e dos trabaIhadores necessitam ultrapassar o conformismo social, característica da adaptação à sociedade de classes e à resolução de problemas imediatos.

Os sujeitos que produzem a sociedade em sua totalidade sobrevêm de um processo violento de expropriação do valor construído por eles próprios. Assim, o Estado moderno opera como um aparelho legitimador dessa ordem banal, ao mesmo tempo em que se oferece direitos a essas classes de se apropriarem de tudo que é produzido pela classe trabaIhadora. Desta feita:

[...] o Estado é o produto da sociedade num estágio específico do seu desenvolvimento; é o reconhecimento de que essa sociedade se envolveu numa autocontradição insolúvel, e está rachada em antagonismos irreconciliáveis, incapazes de ser exorcizados. No entanto, para que esses antagonismos não destruam as classes com interesses econômicos conflitantes e a sociedade, um poder, aparentemente situado acima da sociedade, tornou-se necessário para moderar o conflito e mantê-lo nos limites da "ordem"; e esse poder, nascido da sociedade, mas se colocando acima dela e, progressivamente, alienando-se dela, é o Estado (ENGELS apud HARVEY, 2006, p. 79-80).

Pelo exposto é possível dirimir que em uma sociedade que busca defender o estado democrático de direito, ainda que entendamos que o direito é uma instituição burguesa e, portanto esta afirmação é mais um flagelo para classe trabalhadora, necessita de políticas que mitiguem a pobreza e que a eliminem do quadro social e que confiram proteção ao trabalhador contra a sanha exploradora do capital e do próprio estado em relação ao trabalho. (MÉSZÁROS, 2007).

Entretanto o que se observa no cenário político brasileiro é o domínio claro dos interesses do grande capital no legislativo e este atendendo cabalmente a estes interesses. Entretanto, o mesmo vale para outras instâncias, como por exemplo, no caso da educação com a pauta em discussão da "escola sem partido", que defende nada mais que uma escola "sem conhecimento", que não socialize os conhecimentos elaborados e sistematizados, impedindo qualquer projeto humanizador e a autonomia de qualquer posicionamento frente às discussões e problemas enfrentados pela sociedade do capital. Esse projeto está em defesa de diversas formas de exploração e opressão que existem em nossa sociedade.

É um projeto político que retira as discussões de gênero da escola e promove um discurso de luta contraà ampla disseminação da falsa premissa da "ideologia de gênero", visto como um empenho a favor da família e aos valores de uma sociedade cristã, que busca pela conservação dos papéis de gênero tradicionais, impondo a manutenção das desigualdades de gênero. 
Criouse uma falácia apelidada de "ideologia de gênero", que induziria à destruição da família "tradicional", à legalização da pedofilia, ao fim da "ordem natural" e das relações entre os gêneros, e que nega a existência da discriminação e violência contra mulheres e pessoas LGBT comprovadas com dados oficiais e estudos científicos. Utilizou-se de desonestidade intelectual, formulando argumentos sem fundamentos científicos e replicando-os nas mídias sociais para serem engolidos e regurgitados pelos fiéis acríticos que os aceitam como verdades inquestionáveis. Utilizou-se também de uma espécie de terrorismo moral, atribuindo o status de demônio às pessoas favoráveis ao respeito à igualdade de gênero e diversidade sexual na educação, além de intimidar profissionais de educação com notificações extrajudiciais com ameaça de processo contra quem ousasse abordar esses assuntos na sala de aula. Criou-se um movimento para "apagar" o assunto gênero do currículo escolar (REIS; EGGERT, 2017).

Ao mesmo tempo esse projeto quer impedir a promoção de discussões políticas sobre a sociedade, com a justificativa de que a escola é apartidária e os conhecimentos socializados são neutros, ações que tendem cada vez mais a fortalecer a desigualdade social, própria da sociedade brasileira. Em primeiro lugar, entendemos o projeto "escola sem partido" partidário, com pretensões de impedir a compreensão das diversas relações entre os seres humanos e o processo de humanização e do trabalho na sociedade do capital. E segundo, que os conhecimentos, tal como a ciência, não são neutros. Pelo contrário, o conhecimento é sempre interessado, o que não impossibilita a objetividade, que se busque-o à explicitação das múltiplas determinações que produzem e explicam os fatos, historicamente acumulado pela humanidade.

A superação desta condição impostas a partir de projetos como a "escola sem partido" implica em políticas que adotem o combate a pobreza, à desigualdade social, a destruição ambiental e ao desrespeito à comunidade ALGBTIQ (Assexuais, Lésbicas, Gays, Bissexuais, Travestis, Transexuais, Intersexuais e os "Não-Binários") marginalizada. O maior desafio, no entanto, é direcionar o acesso aos indivíduos que realmente precisam de tais iniciativas, formando a consciência filosófica como defende Saviani (1996) em sua pedagogia histórico-crítica.

Nesse sentido, a classe proletária ao superar o senso comum, tomam conhecimento da realidade concreta, o que os possibilita passar da condição de "classe em si" para a condição de "classe para si" e capazes de objetivar a transformação social, isto é, enquanto práxis política, visa a transformação revolucionária da sociedade.

Ou seja, uma concepção que concebe o desenvolvimento histórico da humanidade a partir de ações conflituosas, impelidas pela luta de classes, num contexto largamente caracterizado pela contradição, em meio ao desenvolvimento das forças produtivas e das relações sociais de produção. Um projeto que parte da contradição que marca a educação escolar na sociedade capitalista, entre, por um lado, a função específica de socialização do saber sistematizado e, por outro, o fato do conhecimento ser parte dos meios de produção e sua propriedade não poder ser plenamente socializada no capitalismo (MALANCHEN, 2014, p.6).

A necessária participação política para a transformação da sociedade contemporânea só se faz a partir da promoção aos proletariados de uma educação crítica que considere o ambiente e as discussões de gênero e sexualidade mediada na prática social, para que pos- 
sam ultrapassar o imediatismo pautado na empiria fenomêminca da prática social, que por meio da abstração da mente, fortaleçam formas de pensamento que entendam a mesma prática social em sua rica totalidade de relações sociais, na operação das múltiplas determinações da própria prática social. Nesses termos, promove-se a consciência de classe à classe trabalhadora, isto é, de que fazem parte de um projeto e uma força hegemônicopolítica determinado historicamente, que possa articular a educação à uma mudança estrutural da sociedade de classe na busca de se instaurar uma sociedade em que o modo de produção instaurado seja em regime socialista (SAVIANI, 2013).

\section{CONCLUSÕES}

Nosso intuito foi o de contribuir com a educação crítica explicitando a importância das temáticas ambiental, da diversidade e sua relação com as políticas públicas no delicado momento que estamos vivendo que infindáveis questões de ordem social, econômica, ambiental, éticas, entre outras parecem não terem soluções, apesar do grande desenvolvimento científico e tecnológico de nossa sociedade.

A elevada exclusão social, a desigualdade econômica e a crise ambiental apontam à importância de focalizamos as políticas públicas para a superação destas condições impostas pelo modelo atual de produção da vida em sociedade. Este enfrentamento pressupõe uma teoria crítica consistente e uma prática comprometida com a causa operária tanto nos espaços formais como informais. Neste sentido a filosofia da práxis mostra-se o instrumental científico filosófico para a transformação e emancipação humana no atual cenário brasileiro e mundial.

Portanto, ao verificar estas questões no processo educativo e o indicativo de algumas pesquisas realizadas nos últimos anos, observam-se propostas de projetos, pesquisas e propostas teóricas nas escolas e universidades que não problematizam criticamente as situações que tematizam de natureza igual que se verificam um aumento intenso dos problemas ambientais e um ataque às discussões de gênero e sexualidade no contexto da escola pública (TEIXEIRA; TOZONI-REIS; TALAMONI, 2011, BIANCON, 2016; ZANATTA et.al, 2016). Ainda no espaço escolar, estas questões não se apresentam como tema nuclear no currículo e quando se manifesta, na maioria das vezes se vê a partir de projetos transversais, em consequências, por datas comemorativas, à semana do meio ambiente, ao dia da árvore, à projetos de separação do lixo, com propostas sensibilizadoras e conscientizadas do problema ambiental que acreditam por meio desse processo, já transformar o mundo.

\section{REFERÊNCIAS}

BIANCON, Mateus Luiz. A Educação em Sexualidades Crítica: formação continuada de professoras(es) com fundamentos na pedagogia histórico-crítica. Tese (Doutorado em Educação para a Ciência e a Matemática). Universidade Estadual de Maringá, Maringá. 2016. CAMPREGHER PASQUALINI, Juliana; MARTINS, Lígia Márcia. Dialética singular-particularuniversal: implicações do método materialista dialético para a Psicologia. Psicologia \& Sociedade, v. 27, n. 2, 2015. 
GRAMSCI, Antonio. Cadernos do cárcere, 6 v. Rio de Janeiro, Civilização Brasileira, 1999-2002. JANKE, Nadja. Políticas públicas de educação ambiental. Tese (Doutorado) - UNESP, Faculdade de Ciências, Programa de Pós-Graduação em Educação para a Ciência. Bauru, 2012. LUKÁCS, Georg. In.: HOLZ, H.H; KOFLER, L.; ABENDROTH, W. Conversando com Lukács. Tradução de Giseh Vianna Konder. Rio de Janeiro, Paz e Terra, 1969.

Introdução a uma estética marxista: sobre a categoria da particularidade. Rio de Janeiro: Civilização Brasileira, 1978.

Ontologia do ser social: os princípios ontológicos fundamentais de Marx. São Paulo: Livraria Editora Ciências Humanas, 1979.

MALANCHEN, Julia. Currículo e Pedagogia histórico-crítica: a defesa da universalidade dos conteúdos escolares. X ANPED Sul Seminário de pesquisa em educação da Região Sul, 2014. Disponível em http://xanpedsul.faed.udesc.br/arq_pdf/597-0.pdf

MAIA, Jorge Sobral da Silva. Problemáticas da educação ambiental no Brasil: elementos para reflexão. Revista Eletrônica do Mestrado em Educação Ambiental. Rio Grande, v. 32, n. 2, 2015.

MAIA, Jorge Sobral da Silva; BIANCON, Mateus Luiz. (orgs) Educação das Relações de Gênero e sexualidades: reflexões contemporâneas. 1ㅇed. Curitiba: Appris Editora, 2014.

MALANCHEN, JULIA. Currículo e Pedagogia Histórico-crítica: A defesa da universalidade dos conteúdos escolares. In: X Annped sul, 2014, Florianópolis. X Annped Sul. Florianópolis, 2014.

MARX, Karl. O capital: crítica da economia política: livro I. 27ed. Rio de Janeiro: Civilização Brasileira, 2010.

. Contribuição à crítica da economia política. São Paulo: Martins Fontes, 1977.

MARX, Karl; ENGELS, Friedrich. A ideologia alemã. São Paulo: Martin Claret, 2006.

MASSON, Gisele. As contribuições do método materialista histórico e dialético para a pesquisa sobre políticas educacionais. IX ANPED Sul Seminário de pesquisa em educação da Região Sul, 2012. Disponível em http://www.ucs.br/etc/conferencias/index.php/anped sul/\%209anpedsul/paper/viewFile/966/126

MÉSZÁROS, I. O poder da ideologia. São Paulo: Boitempo Editorial, 2007.

REIS, Toni; EGGERT, Edla. Ideologia de gênero: uma falácia construída sobre os planos de educação brasileiros. Educação \& Sociedade, v. 38, n. 138, 2017.

SAVIANI, D. Educação socialista, pedagogia histórico-crítica e os desafios da sociedade de classes. In: LOMBARDI, J. C.; SAVIANI, D. (Orgs.). Marxismo e educação: debates contemporâneos. Campinas, SP: Autores Associados, 2005. p. 223-274.

. Escola e democracia. 40 ed. Campinas/SP: Autores Associados, 2008.

. Educação: do senso comum à consciência filosófica. 11 ed. Campinas/SP: Autores

Associados, 1996.

TEIXEIRA, Lucas André; DE CAMPOS TOZONI-REIS, Marília Freitas; BISCALQUINI TALAMONI, Jandira Líria. A teoria, a prática, o professor e a educação ambiental: algumas reflexões. Olhar de Professor, v. 14, n. 2, 2011. 